\title{
Europe stakes a claim to compete in high-performance computing
}

Paris. For the first time, the most powerful supercomputer in Europe is one that has been designed and built here. Installed last month at the European Laboratory for Particle Physics (CERN) in Geneva, the massive parallel processing (MPP) machine is fuelling Europe's ambitions to become an international player in the high-performance computing (HPC) market.

But if Europe needs reminding that innovative technology alone does not guarantee success, it need not look far. Thinking Machines, the US pioneer of MPP supercomputers, last week filed for protection from creditors under Chapter 11 legislation and fired 140 staff, less than two years after it had seemed poised to oust Cray Research, the company that founded and dominated the HPC industry (see Nature 356, 95; 1992).

Size matters too. Although Thinking Machines and Intel's supercomputer division briefly shared the MPP market, they were speedily dethroned once IBM and Cray brought out their own MPP machines. Cray's T3D, for example, has captured 25 orders in just 11 months, according to the company. 'Mean time to vendor bankruptcy' is now a significant criterion for prospective buyers
- and the big fish seem better bets.

This brief and bloody encounter may dampen Europe's enthusiasm for battle, especially as its pretender is a small UK company, Meiko, with sales of only $£ 12$ million (US\$18 million) in 1992. But despite its size, the company - which designed CERN's machine along with Parsys (UK) and Telmat (France) - beat off US rivals in a David and Goliath showdown last year to win a $\$ 17$ million contract from Lawrence Livermore National Laboratory for its CS-2 MPP machine.

This has lent credibility to Meiko's claim that its technology is internationally competitive. But, according to an official from the European Commission's (EC's) HPC programme, the company is still likely to need massive investment and backup from a large company if it is to succeed. The commission subsidizes research at Meiko, and also bought two CS-2 computers, one for CERN (which is leading one EC HPC project) and the other to be installed at the European Centre for Mathematics in Toulouse in a deal worth around Ecu9 billion (US\$10.97 billion).

Overall, the commission will draw on funds from the 12 member states of the

\section{Supercomputing a RISCy business?}

Parls. Visionary, maverick or dreamer? The jury is out on Stern Systems Computing (SSC) until later this year, when the small French company plans to move its 'breakthrough' supercomputer prototype from the basement of the Advanced Computer Research Institute in Lyon into the cold light of the market.

Nobody can say SSC is a 'me too' company. While the entire supercomputing industry is shifting towards massive parallel processing (MPP), SSC is ploughing its own furrow with a design based on extending Reduced Instruction Set Computing (RISC) - - as used in workstations - to high-performance computing systems.

Adrian Wise, SSC's vice-president of sales and marketing, predicts that industry will prefer SSC's machine, a hybrid between MPP and traditional vector supercomputers, because it would be able to run software written for vector machines at the price/performance ratio of an MPP one. $\mathrm{He}$ dismisses the industry's claim (see above) that the software problems that have dogged MPP are ending. "I've been hearing that for 20 years, and we'll be hearing it for another 20 ," he says.
But some analysts are sceptical of SSC's claims. "Anybody can design the world's best supercomputer, getting it to work in the market is another question," says one. "It's another approach, and its very risky," says one official from the European Commission's high-performance computing programme: "it's still at the R\&D stage".

SSC will also produce purpose-built systems, whereas the current trend is to use cheaper off-the-shelf chips. Wise admits SSC's hardware will cost more than rival products. But he is convinced savings on software development will more than make up for the difference.

What nobody disputes is SSC's success in raising cash. The European Union (EU) and private investors have poured $\mathrm{FFr} 315$ million (US\$58.9 million) into the company since its startup four years ago, over half from the EU alone. Many ascribe this success to the personality of SSC's founder and chief executive, Jacques Stern, formerly chairman of the French state-owned computer company, Bull. Cray Research and Digital Equipment also hold minor

Declan Butler equity stakes in the company.

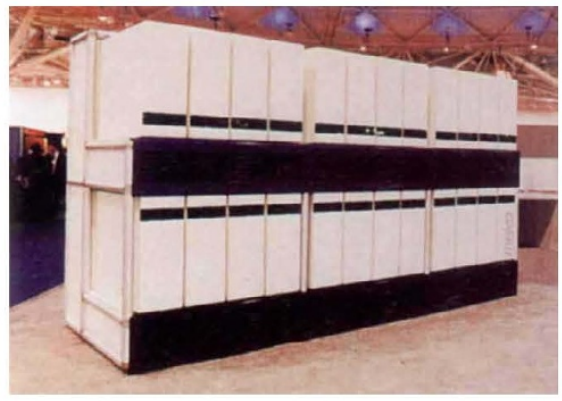

Melko's CS-2 MPP supercomputer was recently Installed at CERN.

European Union (EU) to spend Ecu240 million on high-performance computing between 1995 and 1998. More than half of this will go, not on hardware development, but on overcoming the lack of software that is the main bottleneck to growth of MPP.

MPP machines share out tasks among hundreds or thousands of nodes, each a relatively cheap chip coupled to a memory. They are faster and cheaper than traditional vector supercomputers, which push data, production-line fashion, along just a few very powerful - but purpose-designed and thus highly expensive - chips.

But coordinating MPP demands new architectures and algorithms, and software written for vector computers, which can be based on decades of work, will often not run on these. Modifying programmes can take years, demand an army of $\mathrm{PhDs}$, and cost more than the supercomputer. Not surprisingly, some users, especially commercial ones, are reluctant to switch to MPP.

This may now be changing. For one thing, the off-the-shelf chips used in MPP have grown faster and more powerful. This means that fewer nodes - and less programming - are needed. Chips have also become more compatible with industry standards, such as Unix.

Some observers, such as Chris Elliot of Smith Systems Engineering (UK), a company that advises on supercomputer purchases, also argue that the main obstacle to parallel programming is cultural, and that this too is beginning to change.

"We've got used to going to enormous trouble making parallel problems into serial ones to run on normal computers, and then complaining we can't run them parallel," Smith says. Investment by large companies in MPP is encouraging users to take the risk to start programming MPP from scratch, he says. "MPP is the future."

"The best opportunity for Europe, and everybody, is to develop and use MPP software," says Chris Willard, manager of 